\title{
Optimization of Cutting Parameters When Surface Milling with Face Milling Tool According to the Stages of Response Surface Method
}

\author{
Nguyen Hong Son ${ }^{1, *}$, Do Duc Trung² \\ ${ }^{1}$ Center for Mechanical Engineering, Hanoi University of Industry, Vietnam \\ ${ }^{2}$ Faculty of Mechanical Engineering, Hanoi University of Industry, Vietnam
}

Received December 26, 2019; Revised March 18, 2020; Accepted April 27, 2020

Copyright $\odot 2020$ by authors, all rights reserved. Authors agree that this article remains permanently open access under the terms of the Creative Commons Attribution License 4.0 International License

\begin{abstract}
This paper presents the optimization of cutting parameters when surface milling according to the stages of the response surface method. The implemented stages of the response surface method include the screening design, initial experiments and response surface design. The objective of the screening design is to select the input parameters for the next experimental stages. The goal of the initial experiments is to check the choice range of the input parameters ensures that the output function is extreme point or not. The aim of response surface design is to build the relationship between output parameters and the input parameters. The machined material in this study is C45 steel, while the used cutting tool is the face mill with PVD-coated inserts. Accordingly, the optimal values of cutting parameters including cutting speed, feed rate and depth of cut are determined at $230(\mathrm{~m} / \mathrm{min}), 0.23$ $(\mathrm{mm} /$ toolpath) and $0.888(\mathrm{~mm})$, respectively. In case of machining with this cutting parameter, the surface roughness of workpiece reaches the smallest value, only about $0.15 \mu \mathrm{m}$.
\end{abstract}

Keywords Cutting Parameters, Milling C45 Steel with Face Milling Tool, Optimization, Response Surface Method

\section{Introduction}

The surface roughness of workpieces when machined by machining methods is always a parameter that significantly affects the worktability and life of the workpieces. Therefore, surface roughness is often chosen as a criterion to evaluate the efficiency of the machining process. The surface roughness of workpieces depends on many parameters. In particular, the cutting parameters are usually known as those that have a complicated effect on the surface roughness. In comparison with other parameters, the cutting parameters are those that can be simply adjusted during machining process. For that reason, many studies have been carried out to determine the optimal value of the cutting parameters of machining processes by different methods. Tanveer Hossain Bhuiyan et al. [1] studied the optimization of cutting parameters when turning AISI 1040 steel by genetic algorithms. In this study, the optimum values of cutting speed and feed rate were $142.284(\mathrm{~m} / \mathrm{min})$ and $0.029(\mathrm{~mm} / \mathrm{rev})$, respectively. And, in this case, the optimized cutting force was $140.246(\mathrm{~N})$.

Neeraj Saraswat et al. [2] studied the optimization of cutting parameters for mild steel turning by Taguchi method. The optimum values of cutting velocity, feed rate, and depth of cut that were determined were $60(\mathrm{~m} / \mathrm{min}), 0.1$ $(\mathrm{mm} / \mathrm{rev})$, and $0.4(\mathrm{~mm})$, respectively. With these cutting conditions, the optimized value of surface roughness was $2.5 \mu \mathrm{m}$.

Pankaj Kumar Sahu et al. [3] studied on the determination of optimal cutting parameters when turning aluminum by Taguchi method. In this study, the optimum values of cutting velocity, feed rate, depth of cut that were determined were $35(\mathrm{~m} / \mathrm{min}), 0.15(\mathrm{~mm} / \mathrm{rev})$, and 1.25 $(\mathrm{mm})$, respectively.

Nguyen Hong Son et al. [4] applied genetic algorithm (GA) to determine the optimal value of cutting parameters when turning SKD11 steel. In this study, the smallest surface was $0.47 \mu \mathrm{m}$ that was determined at a cutting velocity of $219.8(\mathrm{~mm} / \mathrm{min})$, a feed rate of $0.05(\mathrm{~mm} / \mathrm{rev})$, and a cutting depth of $0.299(\mathrm{~mm})$.

Kirankumar Ramakantrao Jagtap et al. [5] studied the optimization of cutting parameters when grinding AISI 1040 steel on cylindrical grinder by Taguchi method. In this study, the $\mathrm{Al}_{2} \mathrm{O}_{3}$ grinding wheel with an outer diameter of $300(\mathrm{~mm})$ was used for grinding AISI 1040 steel with a 
diameter of $33(\mathrm{~mm})$. From the experimental results, they have determined the optimal values of parameters that included the depth of cutting, workpiece speed, number of passes, and grinding wheel speed were $0.5(\mathrm{~mm}), 80$ (rev/min), 6 (passes), and 1910 (rev/min), respectively. In this case, the machined surface roughness had a minimum value of $0.22 \mu \mathrm{m}$.

Deepak Pal et al. [6] applied the Taguchi method to determine the optimal value of cutting parameters when when grinding three types of steel EN 24, EN31 and die steel on cylindrical grinder. All three types of steel were heat-treated to achieve three hardness levels: 50, 55 and 60 HRC. The $\mathrm{Al}_{2} \mathrm{O}_{3}$ grinding wheels were used with three graininess levels $(46,60$ and 80$)$. The research results showed that for all three steel types, the optimal values of the hardness of machining materials, grinding wheel speed, and graininess of the grinding wheel were 55 HRC, 200 (rev/min), and 60, respectively.

R. Gupta et al. [7] applied enumeration method to determine the optimal value of cutting parameters when grinding EN14 material. The parameters that were mentioned in this study included the transverse feed rate, the ratio of grinding wheel speed/workpiece speed, and grinding time. The optimal values of the above parameters that were determined have the corresponding values of $0.02(\mathrm{~mm} /$ stroke $), 29$, and $11(\mathrm{~s})$, and, the surface roughness had the smallest value of $0.38 \mu \mathrm{m}$.

Periyasamy et al. [8] applied the response surface method to determine the optimal value of cutting parameters when grinding steel ASIS 1080. The optimum values of cutting depth, feed rate, and dressing depth of cut that were determined had the values of $0.1(\mathrm{~mm}), 0.2(\mathrm{~mm} /$ stroke), and $0.01(\mathrm{~mm})$, respectively, and then the roughness had the smallest value of $0.18 \mu \mathrm{m}$.

Khan Z.A et al. [9] applied Gray Relational Analysis method to determine the optimal value of the cutting parameters when centerless grinding $\mathrm{X} 45 \mathrm{CrSi} 93$ steel (DIN standard). The optimum values of dressing feed when dressing, grinding feed, dwell time, and cycle time were $5(\mathrm{~mm} / \mathrm{min}), 6(\mathrm{~mm} / \mathrm{min}), 2.5(\mathrm{~s})$ and $11(\mathrm{~s})$, respectively. In this case, the surface roughness has the smallest value of $0.44 \mu \mathrm{m}$.

Phan Bui Khoi et al. [10] applied the response surface method to determine the optimal value of parameters in machining process when centerless grinding 20X-carbon infiltration steel. Four parameters of the machining process that were mentioned in this study included the center height angle, the dressing feed-rate, the in-feed speed, and the control wheel velocity. The results of this study showed that the optimal values of the four above parameters were 7.90, $241.41(\mathrm{~mm} / \mathrm{min}), 7.98(\mu \mathrm{m} / \mathrm{s})$ and $27.76(\mathrm{~m} / \mathrm{min})$, respectively. When machining with the values of the above parameters, the surface roughness of the machined part had a minimum value of $0.309 \mu \mathrm{m}$.

Lohithaksha M. Maiyar et al. [11] applied the Taguchi method and the Gray Relational Analysis method to determine the optimal value of cutting parameters when grinding Inconel 718 Super Alloy. The optimum values of cutting speed, feed rate, and depth of cut that were determined in this study had the values of $75(\mathrm{~m} / \mathrm{min}), 0.06$ $(\mathrm{mm} /$ tooth), and $0.4(\mathrm{~mm})$, respectively. With these values, the surface roughness had the smallest value of $0.19 \mu \mathrm{m}$.

João EduardoRibeiro et al. [12] applied the Taguchi method to determine the optimal value of cutting parameters when milling steel 1-2738. The optimal values of cutting speed, feed rate, axial depth, and radial depth were $300(\mathrm{~mm} / \mathrm{min}), 0.3(\mathrm{~mm} / \mathrm{tooth}), 0.1(\mathrm{~mm})$, and 1.0 $(\mathrm{mm})$, respectively. With these values, the minimum value of roughness was $1.1 \mu \mathrm{m}$.

Raneen Abd Ali et al. [13] applied the response surface method to optimize the Al-2024-T4 aluminum alloy milling process. The optimum values of cutting speed, feed rate, and depth of cut that were determined in this study had values of $70(\mathrm{~m} / \mathrm{min}), 0.06(\mathrm{~mm} / \mathrm{tooth})$ and, $0.6(\mathrm{~mm})$, respectively. When machining with the above optimal values, the surface roughness had a minimum value of 0.14 $\mu \mathrm{m}$.

Naga Prasad [14] has optimized the aluminum alloy milling process by Taguchi method. In this study, the optimum values of the tool rotation speed, feed rate, and depth of cut that were determined had the values of 3500 (rev/min), $200(\mathrm{~mm} / \mathrm{min})$, and $0.4(\mathrm{~mm})$, respectively. The above optimization studies showed that there are many optimal methods that have been successfully used in determining the optimal conditions of different machining processes (turning, milling, grinding, etc.). The parameters that were often selected by scientists to determine the optimum value were the parameters for the cutting mode. However, the optimum values of the cutting mode depend on the specific machining conditions.

In this paper, the optimal value of the cutting parameters when milling C45 steel with face milling tool shall be determined. The optimization technique used in this study is performed in a sequence of stages of the response surface method.

\section{Response Surface Method}

The stages of the response surface method include, Screening experiments, Initial Experiments, Path of steepest ascent, and Response surface design. The main content as well as the targets of each stage can be summarized as follows [15]:

Stage 1: Screening experiments. In this stage, $2 \mathrm{k}$ experiments shall be conducted, where $\mathrm{k}$ is the number of parameters to be screened. The purpose of this stage is to eliminate parameters with insignificant effect on evaluation criteria. However, many studies $[16,17]$ show that where the number of input parameters is little, and there are only a few parameters with insignificant effect on evaluation criteria, they can still be retained to do 
experiments in the next stages. The purpose of retaining these parameters is to find out total extremes instead of only local extremes (internal extremes) of optimization problem.

Stage 2: Initial experiments. Such experiments are conducted after conducting screening experiments for selection of experimental variables to be further investigated. In this phase, the central experimental points will be added. The purpose of this stage is to check if the range of input parameters contains the extreme point of the elevation criteria or not. If the range of input parameters in this stage has not yet determined the extremes of evaluation criteria, move to stage 3 and in the contrary case, immediately move to stage 4 .

Stage 3: Path of steepest ascent. If the experimental range is still far from extreme area, experiments should be conducted to quickly find the extreme zone. The basic task of this stage is to determine the incremental values for each experimental variable (each input parameter). Then, conduct experiments with new values of the variables until the target function reverses and changes value.

Stage 4: Response surface design. Once in the extreme vicinity, conduct experiments to describe the in-out relationship between in-put parameters and out-put parameters in the form of high-order function (high-order regression, usually quadratic regression). Based on these regressions, we will determine the optimal value of the input parameters in order to satisfy a specific requirement of evaluation criteria (out-put parameters).

\section{Optimization Experiments in Milling Process Using Stages of the Response Surface Method}

\subsection{Experimental System}

The experiments are conducted on CNC-Foxconn milling machine. The cutting tool used in this study is face milling tool with four PVD-coated inserts. The experimental material of workpiece in this study is $\mathrm{C} 45$ steel, with dimensions of length $\mathrm{x}$ width $\mathrm{x}$ height of $80 \times 35 \times 35$, respectively $(\mathrm{mm})$.

Surface roughness is measured at each component by TESa-rugosurrf 10.G. Roughness is measured at least three times on each component. The surface roughness value in each test is the average of successive measurements.

\subsection{Experiments by Response Surface Method}

In this part, tests will be carried out in stages of the response surface method. At the screening design stage, each cutting parameter has two levels of coding values of -1 and +1 , as shown in Table 1 . During this stage, $2^{\mathrm{k}}=8$ tests will be conducted, as shown in Table 2. Surface roughness measurement results are summarized in Table 2.

Table 1. Values at levels of input parameters in the screening design

\begin{tabular}{|c|c|c|c|}
\hline \multirow{2}{*}{ Codes } & \multicolumn{3}{|c|}{ Values at the levels } \\
\cline { 2 - 4 } & $\begin{array}{c}\text { Cutting speed } \\
(\mathrm{m} / \mathrm{min})\end{array}$ & $\begin{array}{c}\text { Feed rate } \\
(\mathrm{mm} / \text { tooth })\end{array}$ & $\begin{array}{c}\text { Depth of cut } \\
(\mathrm{mm})\end{array}$ \\
\hline-1 & 118.4 & 0.188 & 0.4 \\
\hline+1 & 201.6 & 0.272 & 0.8 \\
\hline
\end{tabular}

Table 2. Screening design matrix and results

\begin{tabular}{|c|c|c|c|c|c|c|c|}
\hline \multirow{2}{*}{ No. } & \multicolumn{3}{|c|}{ Codes } & \multicolumn{3}{|c|}{ Actual values } & \multirow{2}{*}{$\begin{array}{l}\mathrm{Ra}, \\
\mu \mathrm{m}\end{array}$} \\
\hline & $\mathrm{V}$ & $\mathrm{f}$ & $\mathrm{t}$ & $\begin{array}{c}\mathrm{v}, \\
\mathrm{m} / \mathrm{min}\end{array}$ & $\begin{array}{c}\mathrm{f}, \\
\mathrm{mm} / \text { tooth }\end{array}$ & $\begin{array}{c}\mathrm{t}, \\
\mathrm{mm}\end{array}$ & \\
\hline 1 & -1 & -1 & -1 & 118.4 & 0.188 & 0.4 & 1.422 \\
\hline 2 & 1 & -1 & -1 & 201.6 & 0.188 & 0.4 & 0.566 \\
\hline 3 & -1 & 1 & -1 & 118.4 & 0.272 & 0.4 & 3.894 \\
\hline 4 & 1 & 1 & -1 & 201.6 & 0.272 & 0.4 & 1.708 \\
\hline 5 & -1 & -1 & 1 & 118.4 & 0.188 & 0.8 & 1.596 \\
\hline 6 & 1 & -1 & 1 & 201.6 & 0.188 & 0.8 & 0.488 \\
\hline 7 & -1 & 1 & 1 & 118.4 & 0.272 & 0.8 & 4.068 \\
\hline 8 & 1 & 1 & 1 & 201.6 & 0.272 & 0.8 & 1.873 \\
\hline
\end{tabular}




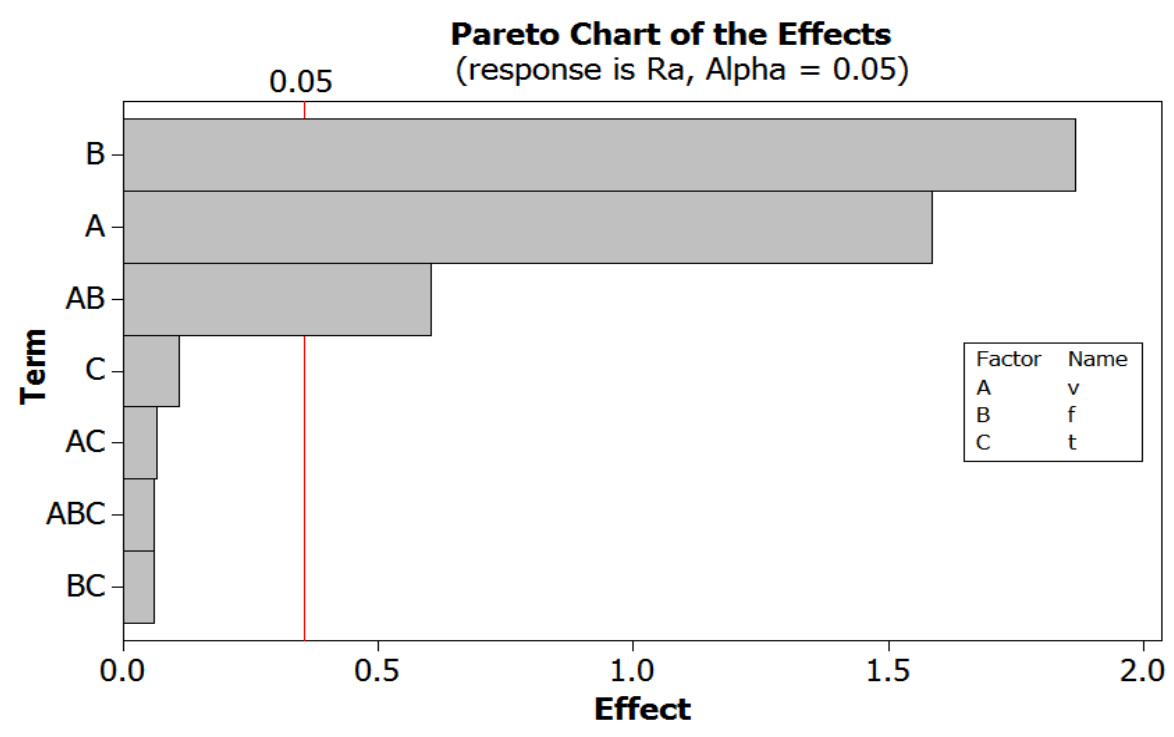

Figure 1. Pareto chart

Minitab 16 software is used to analyze the experimental results in Table 2, Pareto diagram shows the effect of cutting parameters on surface roughness as shown in Figure 1.

See Figure 1 shows that, the cutting speed and feed rate have a great influence on the surface roughness of the workpieces, therefore, two such parameters will be kept for experiments in the next stages. For the depth of cut, there is little effect on surface roughness, however, for the purpose of finding the optimal set of values for all three parameters surveyed in the total extreme form. Therefore, the depth of cut will be kept to conduct experiments in the initial test stage $[16,17]$.

During the initial test stage, six experimental points will be added at the central point (corresponding to coding level $0)[15,18]$. Experimental results in this stage are presented in Table 3.

Table 3. Experiments at the central point and results

\begin{tabular}{|c|c|c|c|c|c|c|c|}
\hline \multirow{2}{*}{ No. } & \multicolumn{3}{|c|}{ Codes } & \multicolumn{3}{|c|}{ Actual values } & \multirow{2}{*}{$\mathrm{Ra}, \mu \mathrm{m}$} \\
\hline & $\mathrm{v}$ & $\mathrm{f}$ & $\mathrm{t}$ & $\mathrm{v}, \mathrm{m} / \mathrm{min}$ & $\mathrm{f}, \mathrm{mm} /$ tooth & $\mathrm{t}, \mathrm{mm}$ & \\
\hline 1 & 0 & 0 & 0 & 160 & 0.23 & 0.6 & 1.462 \\
\hline 2 & 0 & 0 & 0 & 160 & 0.23 & 0.6 & 1.459 \\
\hline 3 & 0 & 0 & 0 & 160 & 0.23 & 0.6 & 1.642 \\
\hline 4 & 0 & 0 & 0 & 160 & 0.23 & 0.6 & 1.557 \\
\hline 5 & 0 & 0 & 0 & 160 & 0.23 & 0.6 & 1.459 \\
\hline 6 & 0 & 0 & 0 & 160 & 0.23 & 0.6 & 1.622 \\
\hline
\end{tabular}

Summarize the experimental results in tables 2 and 3, then, make an ANOVA analysis, with the model of grade 2 surface roughness, the results are as shown in Table 4. 
Table 4. ANOVA analysis for the stage of initial experiments

\begin{tabular}{|c|c|c|c|c|c|c|}
\hline \multicolumn{7}{|c|}{ Analysis of Variance for Ra } \\
\hline Source & DF & Seq SS & Adj SS & Adj MS & $\mathrm{F}$ & $\mathrm{P}$ \\
\hline Regression & 7 & 13.3793 & 13.3793 & 1.91132 & 262.12 & 0.000 \\
\hline Linear & 3 & 12.0330 & 12.0330 & 4.01100 & 550.07 & 0.000 \\
\hline $\mathrm{v}$ & 1 & 5.0324 & 5.0324 & 5.03238 & 690.14 & 0.000 \\
\hline $\mathrm{f}$ & 1 & 6.9770 & 6.9770 & 6.97698 & 956.83 & 0.000 \\
\hline $\mathrm{t}$ & 1 & 0.0237 & 0.0237 & 0.02365 & 3.24 & 0.122 \\
\hline Square & 1 & 0.6001 & 0.6001 & 0.60013 & 82.30 & 0.000 \\
\hline $\mathrm{v}^{*} \mathrm{v}$ & 1 & 0.6001 & 0.6001 & 0.60013 & 82.30 & 0.000 \\
\hline Interaction & 3 & 0.7461 & 0.7461 & 0.2487 & 34.11 & 0.000 \\
\hline $\mathrm{v}^{*} \mathrm{f}$ & 1 & 0.7302 & 0.7302 & 0.73024 & 100.15 & 0.000 \\
\hline $\mathrm{v}^{*} \mathrm{t}$ & 1 & 0.0085 & 0.0085 & 0.00852 & 1.17 & 0.321 \\
\hline$f^{*} \mathrm{t}$ & 1 & 0.0074 & 0.0074 & 0.00738 & 1.01 & 0.353 \\
\hline Res. Error & 6 & 0.0438 & 0.0438 & 0.00729 & & \\
\hline Lack-of-Fit & 1 & 0.0074 & 0.0074 & 0.00738 & 1.01 & 0.360 \\
\hline Pure Error & 5 & 0.0364 & 0.0364 & 0.00727 & & \\
\hline Total & 13 & 13.4230 & & & & \\
\hline
\end{tabular}

See Table 4 shows that the P-value of Lack-of-Fit is 0.360 , which is much higher than the significance level (normally, the significance level is chosen at $0.05[15,18]$ ). On this basis, it can be seen that it is completely suitable to use the quadratic function to describe the relationship between surface roughness and cutting parameters in the surveyed value range of input parameters. In other words, the surveyed range of parameters including cutting speed of $118.4 \mathrm{~m} / \mathrm{min} \div 201.6 \mathrm{~m} / \mathrm{min}$; feed rate of 0.188 $\mathrm{mm} /$ tooth $\div 0.272 \mathrm{~mm} /$ tooth and depth of cut of $0.4 \mathrm{~mm} \div$ $0.8 \mathrm{~mm}$ ensures the response surface roughness function has extreme. Therefore, according to studies [15-18], the path of steepest ascent may be ignored and immediately move to the stage of response surface design.

Table 5. Experiments on axial points

\begin{tabular}{|c|c|c|c|c|c|c|c|}
\hline \multirow{2}{*}{ No. } & \multicolumn{3}{|c|}{ Codes } & \multicolumn{3}{c|}{ Actual values } & \multirow{2}{*}{$\begin{array}{c}\mathrm{Ra} \\
\mu \mathrm{m}\end{array}$} \\
\cline { 2 - 7 } & $\mathrm{v}$ & $\mathrm{f}$ & $\mathrm{t}$ & $\begin{array}{c}\mathrm{v}, \\
\mathrm{m} / \mathrm{min}\end{array}$ & $\begin{array}{c}\mathrm{f}, \mathrm{mm} \\
\text { /tooth }\end{array}$ & $\begin{array}{c}\mathrm{t}, \\
\mathrm{mm}\end{array}$ & \\
\hline 1 & -1.68 & 0 & 0 & 90 & 0.23 & 0.6 & 3.634 \\
\hline 2 & 1.68 & 0 & 0 & 230 & 0.23 & 0.6 & 0.48 \\
\hline 3 & 0 & -1.68 & 0 & 160 & 0.16 & 0.6 & 0.262 \\
\hline 4 & 0 & 1.68 & 0 & 160 & 0.3 & 0.6 & 3.800 \\
\hline 5 & 0 & 0 & -1.68 & 160 & 0.23 & 0.264 & 1.240 \\
\hline 6 & 0 & 0 & 1.68 & 160 & 0.23 & 0.936 & 1.525 \\
\hline
\end{tabular}

In the response surface design, based on the inherited results performed at the screening design and initial experiment, in this stage, the axial experiment points should be added. The axial test is the test where the input parameters receive values at coding levels of $\pm \alpha$, where $\alpha=$ $\left(2^{\mathrm{k}}\right)^{1 / 4}=\left(2^{3}\right)^{1 / 4}=1.68$; The number of axial experiment points is $2 * \mathrm{k}=6[15,18]$. The results of axial experiments are presented in Table 5 .

Summarize experiments in all three stages (tables 2, 3, 5) and make an analysis of results by Minitab 16 statistical software, the results are presented in Table 6 .

Table 6. Results of experiment data analysis

\begin{tabular}{|c|c|c|c|c|}
\hline \multicolumn{5}{|c|}{ Regression Statistics } \\
\hline Multiple R & 0.9923 & & Adjusted $\mathrm{R}^{2}$ & 0.9708 \\
\hline R Square & 0.9846 & & Stan. Error & 0.2030 \\
\hline \multicolumn{5}{|c|}{ ANOVA } \\
\hline & $\mathrm{df}$ & SS & MS & $\mathrm{F}$ \\
\hline Regression & 9 & 26.38242 & 2.93138 & $7.01 * 10^{-8}$ \\
\hline Residual & 10 & 0.4119 & 0.04119 & \\
\hline \multirow[t]{2}{*}{ Total } & 19 & 26.79432 & & \\
\hline & Coefficients & Stan. Error & t Stat & P-value \\
\hline Intercept & 1.4530 & 0.0828 & 17.5553 & 0.0000 \\
\hline $\mathrm{v}$ & -0.9065 & 0.0549 & -16.4995 & 0.0000 \\
\hline $\mathrm{f}$ & 0.9832 & 0.0549 & 17.8946 & 0.0000 \\
\hline $\mathrm{t}$ & 0.0670 & 0.0549 & 1.2198 & 0.2505 \\
\hline $\mathrm{v}^{*} \mathrm{v}$ & 0.1738 & 0.0535 & 3.2462 & 0.0088 \\
\hline$f^{*} \mathrm{f}$ & 0.2412 & 0.0535 & 4.5038 & 0.0011 \\
\hline$t^{*} t$ & 0.0114 & 0.0535 & 0.2134 & 0.8353 \\
\hline $\mathrm{v} * \mathrm{f}$ & -0.3021 & 0.0718 & -4.2098 & 0.0018 \\
\hline $\mathrm{v} * \mathrm{t}$ & -0.0326 & 0.0718 & -0.4547 & 0.6591 \\
\hline $\mathrm{f}^{*} \mathrm{t}$ & 0.0305 & 0.0718 & 0.4254 & 0.6795 \\
\hline
\end{tabular}

The data in Table 6 show that: 
The feed rate has the most significant effect on the surface roughness, followed by the effect of cutting speed. Depth of cut has little effect on surface roughness.

The surface roughness value will decrease as the cutting speed is increased and feed rate is decreased.

Only the interaction between the cutting speed and feed rate has a significant effect on surface roughness. Interaction between cutting speed and depth of cut, interaction between feed rate and depth of cut has a negligible effect on surface roughness.

Based on Table 6, the regression showing the relationship between surface roughness and cutting parameters is determined as follows:

$\mathrm{Ra}=1.4530-0.9065 * \mathrm{v}+0.9832 * \mathrm{f}+0.0670 * \mathrm{t}+0.1738 * \mathrm{v}^{2}$ $+0.2412 * \mathrm{f}^{2}+0.0114 * \mathrm{t}^{2}-0.3021 * \mathrm{v} * \mathrm{f}-0.0326 * \mathrm{v} * \mathrm{t}+0.0305 * \mathrm{f}$

* $\mathrm{t}(1)$

Equation (1) has a coefficient of determination (R-Square) $R^{2}=0.9846$, very close to 1 . This affirms that the surface roughness model has a very good (fitness) compability with empirical data. This equation is the basis for determination of the value of the cutting parameters to ensure that surface roughness reaches a specific value.

\subsection{Optimize the Cutting Parameters}

Minitab 16 statistical software is used to solve the optimization problem in determination of optimal values of cutting parameters to ensure that surface roughness has the lowest value. The results are shown in the Figure 2.

See Figure 2 shows that, with the value of desirability $d$ $=0.94613$ - very close to 1 , showing that the probability of reaching the optimal value of surface roughness through the data as in Figure 2 can be over $94 \%$. On this basis, the optimal values of cutting speed, feed rate and depth of cut are determined to be $230(\mathrm{~m} / \mathrm{min}), 0.23(\mathrm{~mm} / \mathrm{tooth})$ and $0.888(\mathrm{~mm})$, respectively. When machining with this set of parameters, the surface roughness reaches a very low value, only about $.15 \mu \mathrm{m}$.

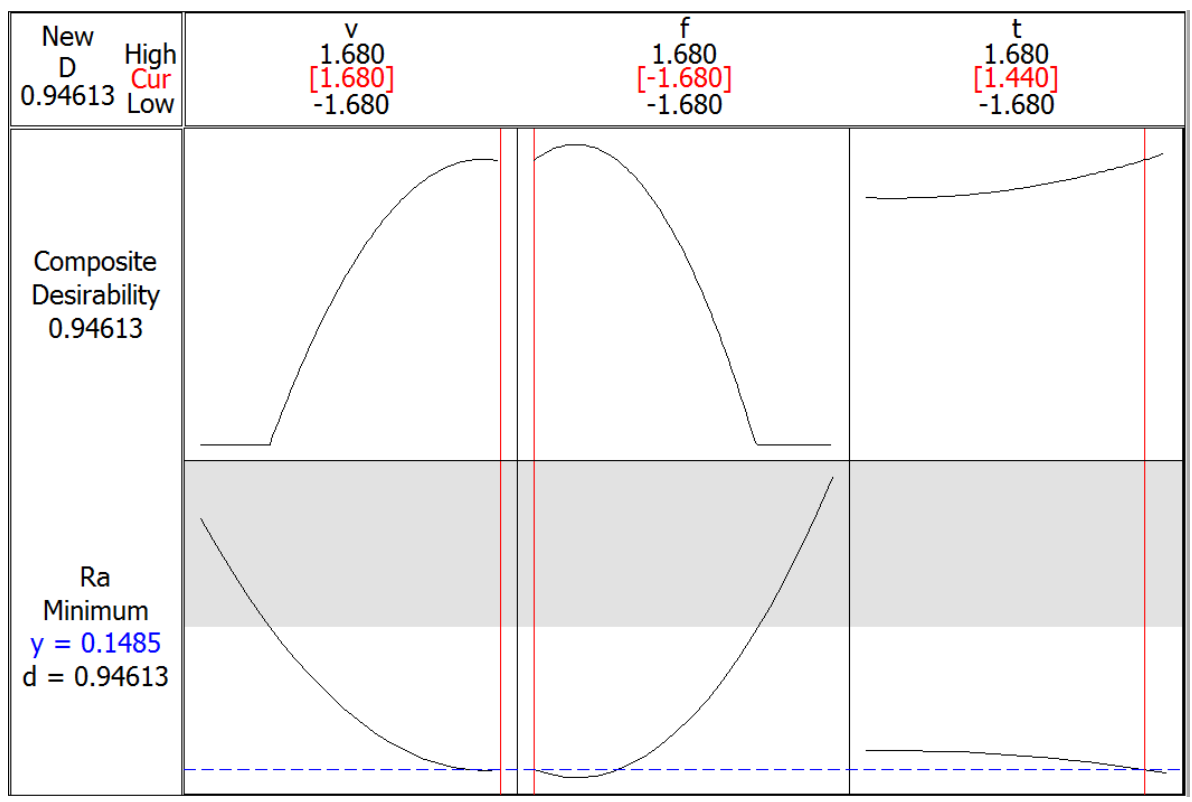

Figure 2. Optimization graph 


\section{Conclusions}

This study specifically analyzed the stages of the response surface method in optimization of $\mathrm{C} 45$ steel with face mill tool, using PVD-coated inserts. In the screening design, the feed rate that was determined had the most influence on the surface roughness, followed by the influence of the cutting speed. Cutting depth was a parameter that does not affect much on the surface roughness. The reason why the depth of cutting had a small effect on surface roughness but still used in the next experimental stage was also analyzed in this study.

The central experiments were added to perform the initial experiments. Using this way, the survey areas of the cutting mode parameters were determined to make sure they contain the extremes. This is the basis to skip the path of steepest ascent.

Axial experimental points were also added to complete the final stage of the experimental process, which is the response surface design stage. After the end of this stage, the relationship between surface roughness and cutting mode parameters was built as the response surface.

Finally, Minitab 16 statistical software has been applied to determine the optimal value of the cutting mode parameters.

In addition to other machining methods, this method is completely applicable.

\section{REFERENCES}

[1] Tanveer Hossain Bhuiyan, Imtiaz Ahmed (2014), Optimization of Cutting Parameters in Turning Process, SAE International by Tanveer Bhuiyan, https://saemobilus. sae.org/content/2014-01-9097/

[2] Neeraj Saraswat , Ashok Yadav, Anil Kumar, Bhanu Prakesh Srivastava (2014), Optimization of Cutting Parameters in Turning Operation of Mild Steel, International Review of Applied Engineering Research, Vol. 4, No. 3, pp. 251-256.

[3] Pankaj Kumar Sahu, Novel Kumar Sahu, Ankit Dubey (2017), Optimization of cutting parameters by turning operation in lather machine, International Journal of Mechanical And Production Engineering, Vol. 5, No. 11, pp. pp.46-51.

[4] Nguyen Hong Son, Hoang Xuan Thinh, Nhu - Tung Nguyen, Do Duc Trung (2019), Influence of Cutting Conditions on the Surface Roughness When Hole Turning Heat-Treated SKD11 Steel, Proceedings of the International Conference on Engineering Research and Applications, Lecture Notes in Networks and Systems, Vol. 104, pp.426-436.

[5] Kirankumar Ramakantrao Jagtap, S.B.Ubale, Dr.M.S.Kadam (2012), Optimization of cylindrical grinding process parametersfor AISI 1040 steel using Taguchi method, International journal of mechanical engineering and technology, Vol. 3. No. 1, pp.226-234.
[6] Deepak Pal, Ajay Bangar, Rajan Sharma, Ashish Yadav (2012), Optimization of Grinding Parameters for Minimum Surface Roughness by Taguchi Parametric Optimization Technique, International Journal of Mechanical and Industrial Engineering, Vol. 1, No. 3, pp.74-78.

[7] R. Gupta, K.S. Shishodia, G. S. Sekhon (2001), Optimization of grinding process parameters using enumeration method, Jounral of Materials processing technology, Vol. 112, pp.63-67.

[8] S. Periyasamy, M. Aravind, D. Vivek, K. S. Amirthagadeswaran, (2014), Optimization of surface grinding process parameters for minimum surface roughness in AISI 1080 using response surface methodology, Advanced Materials Research, Vols. 984-985, pp.118-123.

[9] Khan Z. A, Siddiquee A. N, Kamaruddin S (2012), Optimization of In-feed Centreless Cylindrical Grinding Process Parameters Using Grey Relational Analysis, Pertanika J. Sci. \& Technol, Vol. 20, No. 2, pp.257-268.

[10] Phan Bui Khoi, Ngo Cuong, Do Duc Trung (2014), Study on multi-objective optimization of plunge centerless grinding process, International Journal of Mechanical and Industrial Engineering,Vol. 5. No. 11, pp.140-152.

[11] Lohithaksha M.Maiyar, R.Ramanujam, K.Venkatesan, J.Jerald (2013), Optimization of Machining Parameters for end Milling of Inconel 718 Super Alloy Using Taguchi based Grey Relational Analysis, https://doi.org/10.1016/j.p roeng.2013.09.208.

[12] João EduardoRibeiro, Manuel BrazCésar, HernâniLopes (2017), Optimization of machining parameters to improve the surface quality, https://doi.org/10.1016/j.prostr.2017.07 .182

[13] Raneen Abd Ali, Mozammel Mia, Aqib Mashood Khan, Wenliang Chen, Munish Kumar Gupta, Catalin Iulian Pruncu (2019), Multi-Response Optimization of Face Milling Performance Considering Tool Path Strategies in Machining of Al-2024, Materials (Basel), Vol. 12. No. 7, pp. doi: 10.3390/ma12071013

[14] Ch.S.Naga Prasad (2017), Optimization of Milling Process Parameters of HSS Using Taguchi Parameter Design Approach, International Journal of Innovative Research in Science, Engineering and Technology, Vol. 6. No. 5, pp.9333-9339.

[15] Raymond H. Myers, Douglas C. Montgomery, Christine M. Anderson-Cook (2009), Response Surface Methodology: Process and Product Optimization Using Designed Experiments, John Wiley \& Sons, Inc., 3rd Edition.

[16] Douglas C. Montgomery (2012), Design And Analysis Of Experiments, John Wiln \& Sons, Inc., 5th Edition.

[17] Angela Dean and Daniel Voss (1999), Design and Analysis of Experiments, Springer.

[18] Nguyen Van Du, Nguyen Dang Binh (2011), Design of experiment techniques, Science and technics publishing House. 